6. Shemigon, N.Yu. (2003). The crisis of fundamental norms of social and individual consciousness. Intensification of professional training of students in educational institutions of the humanities: a collection of scientific works. Problems of contemporary art and culture. Kharkov: Print Design. 185-190.
7. Shemigon, N.Yu. (2003). The role of value orientations in the process of preparing future teachers. Problems of updating the content and methods of teaching in educational institutions: a collection of scientific works. Problems of contemporary art and culture. Kharkiv-Lugansk: StyleIzdat. 178-184.

DEMIANIUK Victor,

Honored Worker of Education of Ukraine, director of Rivne Economics-and-Technologies College of National University of Water Management and Nature Management e-mail: vic.demianuk@gmail.com

\title{
PROFESSIONAL-AND-VALUE TRAINING AS A PRACTICAL MEANS OF FORMATION OF FUTURE PROFESSIONALS' VALUE-AND-SENSE SPHERE
}

\begin{abstract}
The meaning of phenomenon of profe?sional value training as a specific system of educational work is exposed in the article. It is shown that profe?sional value training presages using of axiological approach in which boundaries positively creative values have fundamental meanings, while formation student's skills of qualitative selection, development his spiritual, moral and creative foundations are encouraged. It is determined that sphere of objectification of values is value semantic sphere, because the specificity of values are their ability to perform landmark functions, to determine the nature of the vital meaning of the individual.

It is based that formation of value semantic sphere of a personality by means of higher education implies creations a specific educational environment, that have to provide preconditions for participation in socio-cultural
\end{abstract}

processes, that promote objectification of values and formation of values orientation. At the same time, it is shown specificity of professional activity obviously has defining character for formation individual personal qualities, including system of values.

Active assimilation of approved values by society, formation of professional values orientations, devel?pment of value semantic sphere are important components of professional competence of future specialists and determine their competitiveness in professional activity in modern socio-economic conditions.

Keywords: professional value training; value semantic sphere; axiology; pedagogy.

Одержано редакиією 04.10.2018 Прийнято до публікаиї̈ 18.10.2018

DOI 10.31651/2524-2660-2018-14-28-34

ORCID 0000-0002-5804-4941

\section{дОАинний Юрій ОАексійович,}

кандидат педагогічних наук, доцент, докторант кафедри педагогіки і методики технологічної освіти, ГАухівський національний педагогічний університет імені Олександра Довженка

УДК 378.016:376 e-mail: mr.dya69@gmail.com

\section{СТАТИСТИЧНА ОБРОБКА ПОКАЗНИКІВ МОТИВАЦІЙНОГО ТА КОГНІТИВНОГО КОМПОНЕНТА ГОТОВНОСТІ МАЙБУТНІХ ФАХІВЦІВ З ФІЗИЧНОГО ВИХОВАННЯ ДО РЕАБІАІТАЦІЙНОЇ РОБОТИ З ДІТЬМИ 3 ОБМЕЖЕНИМИ ФІЗИЧНИМИ МОЖ- АИВОСТЯМИ}

у статті розглянуто показники мотиваиійного та когнітивного компонента готовності майбутніх бакалаврів з фізичного виховання до реабілітаиійної роботи з дітьми з обмеженими фізичними можливостями.

При вирішенні завдань дослідження реалізаиії практичної складової системи професійної підготовки фахівиів з фізичного виховання до реабілітаиійної роботи з дітьми з обмеженими фізичними можливостями була застосована математична статистика. Для перевірки достовірності покрашення результатів контрольних тестів значення $F$ розрахункового порівнювались з критичними $F_{a, v_{1}, v_{2}}$ із таблииі теоретичного розподілення Фішера для $\alpha=0,05$.

Проведені дослідження дають підставу стверджувати, шо впровадження експериментальної "Програми підготовки фрахівиів з фізичного виховання до реабілітаиійної роботи з дітьми з обмеженими фізичними можливостями" у навчальний процес майбутніх бакалаврів 3 фізичного виховання до реабілітаиійної роботи з дітьми з обмеженими фізичними можливостями суттево впливае на рівень мотиваиійного та когнітивного компонента готовності майбутніх фахівиів до професійної діяльності.

Ключові слова: фахівиі; дослідження; експеримент; реабілітаиія; фрізичне виховання; діти; обмежені фрізичні можливості.

Постановка пробиеми. Актуальною проблемою сучасної педагогічної теорії i практики є процеси професійної підготовки майбутніх фахівців 3 фізичного виховання і спорту до реабікітаційної роботи 3 дітьми 3 обмеженими фізичними можливостями у вищій шкомі. Підвищена увага до цього питання вемикої кількості педагогів, психологів, соціологів зумовлена тим, що діти 3 обмеженими фізичними можливостями в сучасному демократичному суспільстві не мають права залишатися на узбіччі соціальнокумьтурних процесів, системи мюдських взаємин і цінностей. Ці діти мають такі 
ж права, як і здорові: їм необхідно повноцінно навчатися, отримувати загальну освіту та в майбутньому приносити користь суспільству та державі.

Обмеження життєдіяльності визначається повною або частковою втратою здатності чи можкивості до самообслуговування, самостійного пересування, орієнтації, спілкування, навчання, контроҺювання своєї поведінки, а також значним обмеженням обсягу трудової діяльності [1].

Життєвий досвід, практика фізичного виховання та спорту сприяють комплексній реалізації проблеми реабілітації дітей з обмеженими фізичними можливостями, освіти, виховання, формуванню позитивного морального та психофізичного клімату в суспільстві [2].

Аналіз останніх досліджень і пубмікацій. Теоретичний аналіз наукових джерел дозволив вивчити значний досвід 3 теорії та практики професійної підготовки майбутніх фахівців 3 фізичного виховання та спорту у вищій школі. Зокрема, такі їі аспекти: професійна підготовка майбутніх фахівців (Ю.Д. Бойчук, О.А. Дубасенюк, М.Б. Євтух, В.І. Наумчук, В.В. Ягупов й інші); професійна підготовка майбутніх фахівців з фізичного виховання та спорту (T.M. Бугеря, А.Б. Волошко, А.М. Герцик, М.В. Дутчак, Р.П. Карпюк, Т.Ю. Круцевич, Р.В. КАопов, А.П. Конох, О.С. Куц, В.М. Пиатонов, Є.Н. Приступа, О.В. Тимошенко, А.П. Сущенко, Б.М. Шиян, Ю.М. Шкребтій); реалізація принципу неперервності професійної підготовки майбутніх фахівців фізичного виховання та спорту (С.У. Гончаренко, І.А. Зязюн, С.О. Сисоєва, В.О. Кукса, А.П. Сущенко й інші); проблему дітей з обмеженими фізичними можливостями та корекційну роботу 3 такими дітьми розглядали І.Д. Бех, В.І. Бондар, В.В. Засенко, Д.В. Аубовський, О.В. Гузій, О.С. Куц, Є.М. Мастюкова, Г.М. Мерсіянова, В.М. Синьов, Є.Ф. Соботович, А.В. Фомі-чова, О.П. Хохліна, М.Д. Ярмаченко; особливості реабілітаційної роботи засобами фізичної реабілітації з мюдьми, що мають обмеження в розвитку, досліджували I.М. Башкін, Т.В. Бойчук, О.М. Вацеба, А.С. Вовканич,

Т.В. Д'яченко, Ю.О. Аяной, О.К. Мар-ченко, В.М. Мухін, R. Mills [3-6].
Формуаювання ціяей статті. Перевірити достовірність покращення мотиваційного та когнітивного компонента готовності майбутніх бакалаврів 3 фізичного виховання спорту до реабілітаційної роботи 3 дітьми з обмеженими фрізичними можливостями за критичними $F_{a, \gamma 1, \gamma^{2}}$ із таблиці теоретичного розподікення Фішера для $\alpha=0,05$.

Виклад основного матеріалу доспідження. Дия об'єктивного проведення експерименту та виявлення впливу запропонованої програми на мотиваційний та когнітивний компонент готовності майбутніх фахівців з фрізичної культури і спорту з додатковою спеціалізацією за вибором студента "фізкультурнооздоровлювальна та реабілітаційна робота" були розроблені та впроваджені у навчальний процес закладів вищої освіти два опитувальника, та два тесту: опитувальник № 1 (спрямований на виявлення навчально-пізнавальної мотивації студентів 3 фізичного виховання під час навчання у закладах вищої освіти України); опитувальник № 2 (спрямований на виявлення діяльнісної мотивації студентів 3 фізичного виховання під час навчання у закладах вищої освіти України); тести № 1,2 (спрямовані на виявлення когнітивного компонента у студентів з фізичного виховання і спорту під час навчання у закладах вищої освіти України за допомогою рівня засвоєння нормативних навчальних дисциплін).

У результаті проведених досліджень нами було виявлено найбільш впливову навчальну програму. За показниками навчальної підготовценості студенти на початку педагогічного експерименту маоо відрізнялись один від одного $(P<0,05)$ [7-9]. Навчальні заняття проводилися паралельно у дослідних групах за експериментальною програмою підготовки фахівців з фізичного виховання і спорту до реабілітаційної роботи і у контроцьних групах відповідно до розкладу звичайних робочих навчальних планів того чи іншого закладу вищої освіти у середньої кінькості 22,5 години на тиждень.

Аналіз результатів опитувальника № 1 дослідження мотиваційного компонента готовності, спрямованого на вияв^ення навчально-пізнавальної мотивації майбутніх фахівців з фізичного виховання і спорту під час навчання з 2014 по 2017 навчальні роки у закладах вищої освіти України (табл. 1), 
Показники приросту мотиваційного компонента готовності,

спрямованого на виявлення навчально-пізнавальної мотивації майбутніх бакалаврів з фізичного виховання і спорту під час навчання

\begin{tabular}{|c|c|c|c|c|c|c|}
\hline \multirow{2}{*}{ Групи } & \multirow{2}{*}{ Рівень } & \multirow{2}{*}{$\begin{array}{c}\text { Статистичні } \\
\text { показники }\end{array}$} & \multicolumn{4}{|c|}{ Навчамьні заняття (від 0 до 2000) у 2014-2017 н. p. } \\
\hline & & & 500 & 1000 & 1500 & 2000 \\
\hline \multirow{3}{*}{$\mathrm{K} \Gamma$} & \multirow{3}{*}{ Високий } & $\bar{X}$ & 0,5 & 0,5 & 0,25 & 0,25 \\
\hline & & $\sigma$ & 0,58 & 0,58 & 0,5 & 0,5 \\
\hline & & $\mathrm{t}$ & 1,$73 ; P>0,05$ & 1,$73 ; P>0,05$ & $1 ; P>0,05$ & $1 ; P>0,05$ \\
\hline \multirow{3}{*}{$\mathrm{E} \Gamma$} & \multirow{3}{*}{ Високий } & $\overline{\mathrm{X}}$ & 2 & 1,25 & 1,75 & 1,75 \\
\hline & & $\sigma$ & 0,82 & 0,5 & 0,5 & 0,5 \\
\hline & & $\mathrm{t}$ & 4,$9 ; P<0,05$ & $5 ; P<0,05$ & $7 ; P<0,05$ & $7 ; P<0,05$ \\
\hline \multirow{3}{*}{$\mathrm{K} \Gamma$} & \multirow{3}{*}{ Середній } & $\overline{\mathrm{X}}$ & 1,75 & 1,5 & 1,5 & 0,75 \\
\hline & & $\sigma$ & 0,96 & 0,58 & 0,58 & 0,5 \\
\hline & & $\mathrm{t}$ & 3,$65 ; P<0,05$ & 5,$2 ; P<0,05$ & 5,$2 ; P>0,05$ & $3 ; P>0,05$ \\
\hline \multirow{3}{*}{$\mathrm{E} \Gamma$} & \multirow{3}{*}{ Середній } & $\overline{\mathrm{X}}$ & 1,75 & 1,5 & 1,25 & 0,5 \\
\hline & & $\sigma$ & 0,5 & 0,58 & 0,5 & 0,58 \\
\hline & & $\mathrm{t}$ & $7 ; P<0,05$ & 5,$2 ; P<0,05$ & $5 ; P<0,05$ & 1,$7 ; P>0,05$ \\
\hline \multirow{3}{*}{$\mathrm{K} \Gamma$} & \multirow{3}{*}{ Достатній } & $\bar{X}$ & 2,5 & 1,25 & 0,75 & 1 \\
\hline & & $\sigma$ & 0,58 & 0,5 & 0,96 & 0,82 \\
\hline & & $\mathrm{t}$ & 8,$66 ; P<0,05$ & $5 ; P<0,05$ & 1,$56 ; P>0,05$ & 2,$44 ; P<0,05$ \\
\hline \multirow{3}{*}{$\mathrm{E} \Gamma$} & \multirow{3}{*}{ Достатній } & $\overline{\mathrm{X}}$ & 2,5 & 0,75 & 1 & 0,75 \\
\hline & & $\sigma$ & 0,58 & 0,5 & 0,82 & 0,5 \\
\hline & & $\mathrm{t}$ & 8,$6 ; P<0,05$ & $3 ; P<0,05$ & 2,$4 ; P>0,05$ & $3 ; P>0,05$ \\
\hline \multirow{3}{*}{$\mathrm{K} \Gamma$} & \multirow{3}{*}{ Низький } & $\overline{\mathrm{X}}$ & 3,5 & 3 & 1,5 & 0,5 \\
\hline & & $\sigma$ & 1,73 & 1,15 & 1,29 & 0,58 \\
\hline & & $\mathrm{t}$ & $4 ; P<0,05$ & 5,$2 ; P<0,05$ & 2,$3 ; P>0,05$ & 1,$7 ; P>0,05$ \\
\hline \multirow{3}{*}{$\mathrm{E} \Gamma$} & \multirow{3}{*}{ Низький } & $\bar{X}$ & 1 & 1,25 & 0,25 & 1 \\
\hline & & $\sigma$ & 0,82 & 0,5 & 0,5 & 0,82 \\
\hline & & $\mathrm{t}$ & 2,$4 ; P<0,05$ & $5 ; P<0,05$ & $1 ; P>0,05$ & 2,$4 ; P<0,05$ \\
\hline
\end{tabular}

Аналіз результатів опитувальника № 2 дослідження мотиваційного компонента готовності, спрямованого на виявлення діяльнісної мотивації майбу- 


\begin{tabular}{|c|c|c|c|c|c|c|}
\hline \multirow[b]{2}{*}{ Групи } & \multirow[b]{2}{*}{ Рівень } & \multirow{2}{*}{$\begin{array}{c}\text { Статистичні } \\
\text { показники }\end{array}$} & \multicolumn{4}{|c|}{ Навчамьні заняття (від 0 до 2000) у 2014-2017 н. p. } \\
\hline & & & 500 & 1000 & 1500 & 2000 \\
\hline \multirow{3}{*}{$\mathrm{E} \Gamma$} & \multirow{3}{*}{ Достатній } & $\overline{\mathrm{X}}$ & 2 & 0 & 1 & 1,3 \\
\hline & & $\sigma$ & 0,5 & 1,4 & 0,82 & 0,5 \\
\hline & & $t$ & $7 ; P<0,05$ & $0 ; P>0,05$ & 2,$4 ; P<0,05$ & $5 ; P<0,05$ \\
\hline \multirow{3}{*}{$\mathrm{K} \Gamma$} & \multirow{3}{*}{ Низький } & $\overline{\mathrm{X}}$ & 2 & 1 & 0,8 & 1,75 \\
\hline & & $\sigma$ & 1,7 & 0,5 & 1 & 0,25 \\
\hline & & $t$ & 2,$0 ; P>0,05$ & $5 ; P<0,05$ & $2 ; P>0,05$ & 2,$7 ; P<0,05$ \\
\hline \multirow{3}{*}{$\mathrm{E} \Gamma$} & \multirow{3}{*}{ Низький } & $\bar{X}$ & 0,5 & 1 & 0,5 & 1 \\
\hline & & $\sigma$ & 0,58 & 0,5 & 0,6 & 0,8 \\
\hline & & $t$ & 1,$73 ; P>0,05$ & $3 ; P<0,05$ & $2 ; P>0,05$ & $2 ; P>0,05$ \\
\hline \multicolumn{7}{|c|}{$t_{(0,05 ; 3)}=2,35$} \\
\hline
\end{tabular}

найбільший приріст середніх арифметичних різниць високого, середнього, достатнього та низького рівня оцінювання контрольних і експериментальних груп:

1. Після першого контрольного тестування (500 занять): у 2,5 рази в КГ найбільший приріст середніх арифметичних різниць на середньому рівні; у 2

Показники приросту когнітивного компонента готовності

рази в ЕГ найбільший приріст середніх арифметичних різниць на високому рівні; у 2 рази у ЕГ найбільший приріст середніх арифметичних різниць на достатньому рівні; у 2 рази в КГ найбільший приріст середніх арифметичних різниць на низькому рівні.

таблиия 3

\begin{tabular}{|c|c|c|c|c|c|c|}
\hline \multirow{2}{*}{ Групи } & \multirow{2}{*}{ Рівень } & \multirow{2}{*}{$\begin{array}{c}\text { Статистичні } \\
\text { показники } \\
\end{array}$} & \multicolumn{4}{|c|}{ Навчамьні заняття (від 0 до 2000) у 2014-2017 н. p. } \\
\hline & & & 500 & 1000 & 1500 & 2000 \\
\hline \multirow{3}{*}{$\mathrm{K} \Gamma$} & \multirow{3}{*}{ Високий } & $\overline{\mathrm{X}}$ & 2,2 & 1 & 0,4 & 0,4 \\
\hline & & $\sigma$ & 0,84 & 0,71 & 1,14 & 0,89 \\
\hline & & $t$ & 5,$8 ; P<0,05$ & 3,$2 ; P<0,05$ & 0,$8 ; P>0,05$ & $1 ; P>0,05$ \\
\hline \multirow{3}{*}{$\mathrm{E} \Gamma$} & \multirow{3}{*}{ Високий } & $\bar{X}$ & 2,8 & 2 & 0,8 & 1,8 \\
\hline & & $\sigma$ & 1,3 & 0,71 & 0,84 & 1,3 \\
\hline & & $t$ & 4,$8 ; P<0,05$ & 6,$3 ; P<0,05$ & 2,$1 ; P<0,05$ & 3,$08 ; P<0,05$ \\
\hline \multirow{3}{*}{$\mathrm{K} \Gamma$} & \multirow{3}{*}{ Середній } & $\overline{\mathrm{X}}$ & 2,8 & 2,2 & 1,4 & 1 \\
\hline & & $\sigma$ & 0,8 & 1,4 & 0,5 & 0,7 \\
\hline & & $t$ & 7,$4 ; P<0,05$ & $11 ; P<0,05$ & 5,$7 ; P<0,05$ & 3,$1 ; P<0,05$ \\
\hline \multirow{3}{*}{$\mathrm{E} \Gamma$} & \multirow{3}{*}{ Середній } & $\bar{X}$ & 2,2 & 2,2 & 2 & 0,8 \\
\hline & & $\sigma$ & 0,8 & 1,3 & 1 & 2,0 \\
\hline & & $t$ & 5,$8 ; P<0,05$ & 3,$7 ; P<0,05$ & 4,$4 ; P<0,05$ & 0,$8 ; P>0,05$ \\
\hline \multirow{3}{*}{$\mathrm{K} \Gamma$} & \multirow{3}{*}{ Достатній } & $\overline{\bar{X}}$ & 2,2 & 1 & 2 & 0 \\
\hline & & $\sigma$ & 0,8 & 1,4 & 1 & 1 \\
\hline & & $t$ & 5,$8 ; P<0,05$ & 1,$6 ; P>0,05$ & 4,$5 ; P<0,05$ & $0 ; P>0,05$ \\
\hline \multirow{3}{*}{$\mathrm{E} \Gamma$} & \multirow{3}{*}{ Достатній } & $\bar{X}$ & 3,4 & 2,2 & 1,4 & 0,8 \\
\hline & & $\sigma$ & 0,9 & 0,4 & 0,5 & 0,7 \\
\hline & & $t$ & 8,$5 ; P<0,05$ & $11 ; P<0,05$ & 5,$7 ; P<0,05$ & 3,$1 ; P<0,05$ \\
\hline \multirow{3}{*}{$\mathrm{K} \Gamma$} & \multirow{3}{*}{ Низький } & $\bar{X}$ & 2 & 2 & 1,2 & 0,8 \\
\hline & & $\sigma$ & 1 & 1 & 0,8 & 1,1 \\
\hline & & $t$ & 4,$4 ; P<0,05$ & 4,$5 ; P<0,05$ & 3,$2 ; P<0,05$ & 1,$7 ; P>0,05$ \\
\hline \multirow{3}{*}{$\mathrm{E} \Gamma$} & \multirow{3}{*}{ Низький } & $\overline{\bar{X}}$ & 1,2 & 0,6 & 1,4 & 0,8 \\
\hline & & $\sigma$ & 1,3 & 0,5 & 0,5 & 1,3 \\
\hline & & $t$ & 2,$0 ; P>0,05$ & 2,$4 ; P<0,05$ & 5,$7 ; P<0,05$ & 1,$4 ; P>0,05$ \\
\hline \multicolumn{7}{|c|}{$t_{(0,05 ; 3)}=2,35$} \\
\hline
\end{tabular}

2. Після другого контрольного тестування (1000 занять): у 1,3 рази в КГ найбільший приріст середніх арифметичних різниць на середньому рівні; у 1,25 разів у ЕГ найбільший приріст середніх арифметичних різниць на середньому рівні.

3. Після третього контрольного тестування (1500 занять): у 1,25 разів в КГ 
найбільший приріст середніх арифметичних різниць на середньому рівні.

4. Після четвертого контрольного тестування (2000 занять): у 1,75 разів в КГ найбільший приріст середніх арифметичних різниць на низькому рівні; у 1,5 рази в ЕГ найбільший приріст середніх арифметичних різниць на високому рівні.

Аналіз результатів тесту № 1 дослідження когнітивного компонента готовності майбутніх фахівців 3 фізичного виховання і спорту під час навчання 3 2014 по 2017 навчальні роки у закладах вищої освіти України (табц. 3), дав змогу виявити найбільший приріст середніх арифметичних різниць високого, середнього, достатнього та

та низького рівня оцінювання контрольних і експериментальних груп:

1. Після першого контрольного тестування (500 занять): у 2,8 рази в ЕГ найбільший приріст середніх арифметичних різниць на високому рівні; у 2,8 разу у КГ найбільший приріст середніх арифметичних різниць на середньому рівні; в 3,4 разу у ЕГ найбільший приріст середніх арифметичних різниць на достатньому рівні.

2. Після другого контрольного тестування (1000 занять): у 2,2 рази в КГ та ЕГ найбільший приріст середніх арифметичних різниць на середньому рівні; у 2,2 разу у КГ найбільший приріст середніх арифметичних різниць на достатньому рівні.

3. Після третього контрольного тестування (1500 занять): у 2 рази в ЕГ найбімьший приріст середніх арифметичних різниць на середньому рівні; у 2 рази в КГ найбільший приріст середніх арифметичних різниць на достатньому рівні.

4. Після четвертого контрольного тестування (2000 занять): у 1,8 рази в ЕГ найбільший приріст середніх арифметичних різниць на високому рівні.

Аналіз результатів тесту № 2 дослідження когнітивного компонента готовності майбутніх фахівців 3 фізичного виховання під час навчання з 2014 по 2017 навчальні роки у закладах вищої освіти України (табц. 4) дав змогу виявити

Показники приросту когнітивного компонента готовності майбутніх бакалаврів з фізичного виховання і спорту під час навчання

\begin{tabular}{|c|c|c|c|c|c|c|}
\hline \multirow{2}{*}{ Групи } & \multirow{2}{*}{ Рівень } & \multirow{2}{*}{$\begin{array}{l}\text { Статистичні } \\
\text { показники } \\
\end{array}$} & \multicolumn{4}{|c|}{ Навчамьні заняття (від 0 до 2000) у 2014-2017 н. p. } \\
\hline & & & 500 & 1000 & 1500 & 2000 \\
\hline \multirow{3}{*}{$\mathrm{K} \Gamma$} & \multirow{3}{*}{ Високий } & $\bar{X}$ & 1 & 0,5 & 0,5 & 0,25 \\
\hline & & $\sigma$ & 0,82 & 0,58 & 0,58 & 0,5 \\
\hline & & $t$ & 2,$4 ; \mathrm{P}<0,05$ & 1,$7 ; P<0,05$ & 1,$7 ; P>0,05$ & $1 ; P>0,05$ \\
\hline \multirow{3}{*}{$\mathrm{E \Gamma}$} & \multirow{3}{*}{ Високий } & $\bar{X}$ & 5 & 1 & 1,25 & 0,25 \\
\hline & & $\sigma$ & 1,8 & 0,82 & 0,5 & 0,96 \\
\hline & & $t$ & 5,$4 ; P<0,05$ & 2,$4 ; P<0,05$ & $5 ; P<0,05$ & 0,$52 ; P<0,05$ \\
\hline \multirow{3}{*}{$\mathrm{K} \Gamma$} & \multirow{3}{*}{ Середній } & $\bar{X}$ & 2,75 & 1,25 & 1 & 1 \\
\hline & & $\sigma$ & 0,5 & 0,5 & 0,82 & 1,15 \\
\hline & & $t$ & $11 ; P<0,05$ & $5 ; P<0,05$ & 2,$4 ; P<0,05$ & 1,$7 ; P<0,05$ \\
\hline \multirow{3}{*}{$\mathrm{E} \Gamma$} & \multirow{3}{*}{ Середній } & $\bar{X}$ & 0,5 & 1,25 & 1 & 0,25 \\
\hline & & $\sigma$ & 0,58 & 0,5 & 0,82 & 0,5 \\
\hline & & $t$ & 1,$7 ; P<0,05$ & $5 ; P<0,05$ & 2,$4 ; P<0,05$ & $1 ; P>0,05$ \\
\hline \multirow{3}{*}{$\mathrm{K} \Gamma$} & \multirow{3}{*}{ Достатній } & $\bar{X}$ & 2 & 1,5 & 0,75 & 0,5 \\
\hline & & $\sigma$ & 0,82 & 0,5 & 0,96 & 0,58 \\
\hline & & $t$ & 4,$9 ; P<0,05$ & 5,$2 ; P<0,05$ & $3 ; P<0,05$ & 1,$7 ; P>0,05$ \\
\hline \multirow{3}{*}{$\mathrm{E} \Gamma$} & \multirow{3}{*}{ Достатній } & $\bar{X}$ & 1,75 & 1,75 & 1,25 & 1,5 \\
\hline & & $\sigma$ & 0,5 & 0,5 & 0,5 & 1,29 \\
\hline & & $t$ & $7 ; P<0,05$ & $7 ; P<0,05$ & $5 ; P<0,05$ & 2,$3 ; P<0,05$ \\
\hline \multirow{3}{*}{$\mathrm{K} \Gamma$} & \multirow{3}{*}{ Низький } & $\bar{X}$ & 2,5 & 1,25 & 1,75 & 1,5 \\
\hline & & $\sigma$ & 0,58 & 0,5 & 0,96 & 0,58 \\
\hline & & $t$ & 8,$7 ; P<0,05$ & $5 ; P<0,05$ & 3,$6 ; P<0,05$ & 5,$2 ; P<0,05$ \\
\hline \multirow{3}{*}{$\mathrm{E} \Gamma$} & \multirow{3}{*}{ Низький } & $\bar{X}$ & 0,5 & 0,75 & 0,5 & 0,75 \\
\hline & & $\sigma$ & 0,58 & 0,5 & 0,58 & 0,5 \\
\hline & & $t$ & 1,$7 ; P>0,05$ & $3 ; P<0,05$ & 1,$7 ; P>0,05$ & $3 ; P<0,05$ \\
\hline
\end{tabular}


найбільший приріст середніх арифметичних різниць високого, середнього, достатнього та низького рівня оцінювання контрольних і експериментальних груп:

1. Після першого контрольного тестування (500 занять): у 5 разів у ЕГ найбімьший приріст середніх арифметичних різниць на високому рівні.

2. Після другого контрольного тестування (1000 занять): у 1,5 рази в КГ та 1,75 разів у ЕГ найбільший приріст середніх арифметичних різниць на достатньому рівні.

3. Після третього контрольного тестування (1500 занять): у 1,75 рази в КГ найбільший приріст середніх арифметичних різниць на низькому рівні.

4. Після четвертого контрольного тестування (2000 занять): у 1,5 рази в ЕГ найбільший приріст середніх арифметичних різниць на достатньому рівні; у 1,5 рази в КГ найбільший приріст середніх арифметичних різниць на низькому рівHi.

Висновки. проведений експеримент дає можливість виявити вплив експериментальної та загальної програм на мотиваційний та когнітивний компонент готовності майбутніх фахівців з фізичної культури і спорту з додатковою спеціалізацією за вибором студента "фізкультурно-оздоровлювальна та реабілітаційна робота". Впровадження у навчальний процес експериментальної програми підготовки фахівців з фрізичного виховання до реабімітаційної роботи з дітьми 3 обмеженими фізичними можливостями свідчить, що спостерігається достовірне покращення показників мотиваційного та когнітивного компоненту готовності майбутніх бакалаврів $з$ фізичного виховання до професійної діяльності.

Тобто ефективність впливу запровадженої експериментальної програми в значній мірі обумовлена раціональною методикою та навчальним змістом запропонованої програми та робочого навчального плану у процес підготовки майбутніх фахівців з фізичного виховання і спорту.

\section{Список бібліографічних посимань}

1. Долинний Ю.О. Критерії успішності професійної готовності майбутнього фахівця 3 фізичного виховання до реабілітаційної роботи з дітьми з обмеженими фізичними можливостями. Глухівсъкі наукові читання - 2016. Актуальні питання суспільних та гуманітарних наук: Матеріали VI Мiжнародної інтернет-конференції молодих учених і студентів 27-29 вересня 2016 року. ГАухів : РВВ
Глухівського НПУ ім. О. Довженка. 2016. C. $54-58$.

2. Башкін I., Макарова Е., Кавакзе Різік А. Роль і місце фізичної реабілітації у загальній системі охорони здоров'я населення. Теорія $i$ методика фрізичного виховання і спорту. 2006. № 3. С. 2529.

3. Гайволя Р.Ю. До питання професійної підготовки майбутніх фахівців фізичного виховання. Молодіжний науковий вісник: Фізичне виховання $i$ cпорт : зб. наук. пр. Ауцьк: Волин. нац. ун-т ім.



4. Куц О., Аапичак I. Нові технології та моделювання підготовки вчителів фізичної культури. Молода спортивна наука України: Зб. наук. праць з галузі фізичної культури та спорту. Вип. 6: У 4-х т. Аьвів: Українські технології, 2002. Т. 2. С. 539541.

5. Долинний Ю.О. Сучасні теоретичні основи підготовки майбутніх фахівців з фізичного виховання і спорту до реабілітаційної роботи. Педагогика и современные аспекты фризического воспитания: зб. наук. праць II Міжнар. наук.-практ. конф. (21-22 квітня 2016 року) / за заг. ред. Ю.О. Долинного. Краматорськ: ДДМА, 2016. С. 235-241

6. Кукса В. Переорієнтація професійної самосвідомості студента - фізреабілітолога. Теорія $i$ методика фрізичного виховання і спорту. 2002. № 4. С. 40-47.

7. Иванов В.С. Основы математической статистики. М.: Физкультура и спорт, 1990. 175 с.

8. Кремер Н.Ш. Теория вероятностей и математическая статистика. М.: Юнити, 2000. 543 с.

9. Суслаков Б.А. Статистические методы обработки результатов измерений. Спортивная метрология / Под ред. проф. Зациорского В.М. М.: Физкультура и спорт, 1982. С.19-62.

\section{References}

1. Dolinnij Yr.A. (2016). Criteria of success of professional readiness of future specialist of physical education to rehabilitation work with children with limit physical possibilities. Actual questions of social sciences and humanities: Materials of the VI International Internet Conference of Young Scientists and Students September 27-29, Glukhiv: Glukhiv NPO named after O. Dovzhenko. 54-58.

2. Bashkin I., \& Makarova E., \& Kavakze Rizik A. (2006). A role and place of physical rehabilitation are in the general system of health protection population. Theory and methods of physical education and sport. 3. 25-29.

3. Haivolia, R.Yu. (2007). To the question of professi nal preparation of future specialists of physical education. Youth Science Bulletin: Physical Education and Sport: Collection of Scientific Papers. Lutsk: Volyn National University named after Lesya Ukrainka. 3-7.

4. Kucz O., \& Lapichak I. (2002). New technologies and modeling of training of teachers of physical culture. Young sports science of Ukraine: Collection of scientific works in the field of physical culture and sports. Issue 6: In 4 Vol. Lviv: Ukrainian technRlogies. 2. 539-541.

5. Dolinnij, Y. (2016). Modern theoretical bases for training future specialists in physical education and sports for rehabilitation work. Pedagogy and modern aspects of physical education: a collection of scientific papers of the International Scientific and Practical Conference (April 21-22, 2016). In Yu.O. Dolinnij (Ed.). Kramatorsk: DSMA. 235-241.

6. Kuksa, V. (2002). Reorientation of professional selfconsciousness of a student - physiotherapy specialist. Theory and methods of physical education and sport. 4. 40-47. 
7. Ivanov, V.S .(1990). Fundamentals of Mathematical Statistics. Moscow: Physical Education and Sports. $175 \mathrm{p}$.

8. Kremer, N.Sh. (2000). Probability Theory and Mathematical Statistics. Moscow: Unity. 543 p.
9. Suslakov, B.A. (1982). Statistical methods of processing the results of measurements. Sports metrology. In prof. V.M. Zatsiorsky (Ed.). Moscow: Physical Education and Sports. 19-62.

\title{
DOLYNNYI Yuriy,
}

Ph.D in Pedagogy, Associate Professor,

Doctoral Student of Pedagogy and Methodology of Technological Education Department, Oleksandr Dovzhenko Hlukhiv National Pedagogical University

\author{
e-mail:mr.dya69@gmail.com
}

\section{STATISTICAL PROCESSING OF INDICATORS OF MOTIVATIONAL AND COGNITIVE COMPONENT OF READINESS OF FUTURE SPECIALISTS IN PHYSICAL EDUCATION TO REHABILITATION WORK WITH CHILDREN WITH LIMITED PHYSICAL POSSIBILITIES}

\begin{abstract}
Conceptual positions of professional preparation of future specialists on physical education and sport in relation to rehabilitation work with children with limit physical possibilities provide for : quality system of higher education, that answers the requirements of modern professional preparation of future specialists on physical education and sport to rehabilitation work; thorough knowledge by future specialists on physical education and sport of physiology and psychology-pedagogical features of children with physical limitations in development; perfection of state trade education, legislativelynormative base of Ukraine, creation of model of professional preparation of future specialists on physical education and sport to rehabilitation work with children with limit physical possibilities.

Quality system of higher education in direction of physical rehabilitation of people with limit physical possibilities considerably extends limits in methods, facilities and directions of rehabilitation. In collaboration with doctors and workers of social services specialists on physical therapy, ergo internists, physical rehabilitation mortgage bases of the national system of physical rehabilitation of people with limit physical possibilities.

Thorough knowledge by future specialists on physical therapy, ergo internists, the physical rehabilitation of physiology and psychology-pedagogical features of children with physical limitations in development needs foremost such knowledge: physician-biologist problems of children with physical limitations in development; basic anatomy-physiologist conformities to law of age-old devel-
\end{abstract}

opment of child; theoretical bases of medical sciences (of basis of general pathology, anatomy, biomechanics of sporting morphology, physiology, physic pathology, hygiene, clinic of internal illnesses, surgical and endocrine diseases, diseases and damages of locum thorium, reflex therapy, physiotherapy, python therapy, manual correction and massage); knowledge of the system and principles of physical rehabilitation; sanitary-hygienic requirements to the terms of realization of employments after a curative physical culture, massage, grant of physical therapy and manual procedures.

Perfection of state trade education is impossible without the co-ordinations actions of different state structures and departments, the task of that must be forming of strategy and tactics, organization and providing of measures of the physical internals of organism, increase of functional possibilities, strengthening of health of population sent to renewal, technical and skilled providing. These program development needs knowledge of features of organizationally-methodological approaches that must take into account the regional features of forming of modern society in different countries. Introduction of such programs is impossible without the adequate normativelylegal, technical and skilled providing.

Keywords: conception; preparation; specialists; physical rehabilitation; child; physical possibilities; physical education; professional preparation; limit.

Одержано редакиією 04.07.2018 Прийнято до публікаиї̈ 18.07.2018

DOI 10.31651/2524-2660-2018-14-34-40

ORCID 0000-0002-5947-314X

ІВАНИЦЬКА Оксана Степанівна,

провідний спеціаліст ректорату,

Національний університет " $\Lambda$ ьівська політехніка"

e-mail: kseniaivanytska@ukr.net

УДК 378

\section{ОСОБАИВОСТІ РЕФОРМУВАННЯ ВИЩОЇ ОСВІТИ У ЄВРОПІ В КОНТЕКСТІ СТУДЕНТОЦЕНТРОВАНОГО НАВЧАННЯ ТА РЕАМІЗАЦІї ТЬЮТОРСТВА I MEHTOPCTBA У $3 B 0$}

(ЗА MATEPIA AMИ KOHФEPEHЦIÏ: «REFORMING EUROPEAN HIGHER EDUCATION FROM POLICY TO PRACTICE», KYIV, JUNE, 08-09, 2018)

Дослідження відображає тендениї розвитку вищої освіти у Свропі, як результат реформування та розширення інтернаціоналізаиї $у$ ЗВО. В статті проаналізовано та систематизовано інформаиію, шо була представлена на конферениіï "Reforming European Higher Education - From Policy to Practice", яка відбулася у Kuєві, 8-9 червня, 2018 року. Дослідження містить аналітичний підсумок дискусій за участю українсъких та німеиьких науковиів, праиівників
Німецької служби академічних обмінів DAAD, Еразмус+ офрісу в Україні та представників Міністерства Освіти і Науки Украӥни. Підведено підсумки дискусій та представлено майбутні бачення. Стаття висвітлюе проблеми в реалізаиії реформ у Європі, зокрема в Німеччині та Україні та обговорення шляхів їх вирішення. В стані проаналізовані питання інтернаціоналізаиії, академічної мобільності, забезпечення якості у вищій освіті, визнання результатів 